(C)2010 IEEE. Personal use of this material is permitted. However, permission to reprint/republish this material for advertising or promotional purposes or for creating new collective works for resale or redistribution to servers or lists, or to reuse any copyrighted component of this work in other works must be obtained from the IEEE. 


\title{
Transmission System Augmentation Based on the Concepts of Quantity Withheld and Monopoly Rent for Reducing Market Power
}

\author{
Mohammad R. Hesamzadeh, Graduate Student Member, IEEE, Nasser Hosseinzadeh, Member, IEEE, and \\ Peter J. Wolfs, Senior Member, IEEE
}

\begin{abstract}
This paper proposes two mathematical structures for considering the market power effect of transmission capacity in transmission augmentation assessment. These mathematical structures use the concepts of monopoly rent and quantity withheld in economics for market power modeling in the assessment process of transmission augmentation. The simultaneous-move and sequential-move games in applied mathematics are used to model the interactions of the transmission network service provider, generating companies, and the market management company in the proposed mathematical structures. The solution concept of Nash equilibria is reformulated as an optimization problem, and the multiple Nash equilibria is tackled through an introduced concept termed worst Nash equilibrium. A numerical solution is developed to solve the proposed mathematical structures. The numerical solution is an island parallel genetic algorithm nested in a standard genetic algorithm. The six-bus Garver's example system and the IEEE 14-bus test system are modified and studied. The results prove the strong mechanism of the developed structures for modeling the market power effect of transmission capacity in the assessment of transmission augmentation.
\end{abstract}

Index Terms-Game theory, market power, Nash equilibria, transmission system augmentation.

\section{NOMENCLATURE}

\section{Abbreviations}

TNSP Transmission network service provider.

GenCo Generating company.

MMC Market management company.

$A_{L} \quad L$-shape area metric.

MR Monopoly rent.

\section{Sets and parameters}

$N \quad$ Set of natural numbers.

$R^{(+)} \quad$ Set of (positive) real numbers.

$L \quad$ Set of candidate transmission lines.

$c_{i j} \quad$ Transmission investment cost between nodes $i$ and $j$.

Manuscript received July 02, 2009; revised July 31, 2009. First published December 28, 2009; current version published January 20, 2010. Paper no. TPWRS-00451-2008.

M. R. Hesamzadeh and N. Hosseinzadeh are with Swinburne University of Technology, Melbourne, Vic. 3122, Australia.

P. J. Wolfs is with Curtin University, Bentley, W.A. 6102, Australia.

Digital Object Identifier 10.1109/TPWRS.2009.2036823 $n_{i j} \quad$ Number of approved circuits for expanding of transmission corridor $i j$.

$n_{i j}^{\max } \quad$ Maximum number of circuits for expanding the transmission corridor $i j$.

$n_{i j}^{0} \quad$ Existing number of transmission lines between nodes $i$ and $j$.

$\gamma_{i j} \quad$ Susceptance of transmission branch between nodes $i$ and $j$.

$P_{\min } \quad$ Minimum price for GenCos' bidding.

$P_{\max } \quad$ Maximum price for GenCos' bidding.

$f_{i j}^{\max } \quad$ Thermal capacity of the branch $i j$

Objectives and decision variables

$\Gamma \quad$ TNSP objective function.

$\pi_{i} \quad$ Profit of GenCo $i$.

$\pi_{i}^{c} \quad$ Profit of GenCo $i$ under competitive conditions.

$c_{i}^{\prime} \quad$ Bidding price of GenCo $i$.

$g_{i}^{c} \quad$ Dispatched capacity of GenCo $i$ under competitive conditions.

$g_{i}^{\max ^{\prime}} \quad$ Bidding quantity of GenCo $i$.

$d_{i}^{c} \quad$ Dispatched demand of retailer $i$ under competitive conditions.

$f_{i j} \quad$ Real power flow vector.

$f_{i j}^{c} \quad$ Real power flow vector under competitive conditions.

$\theta_{i} \quad$ Angle of node $i$.

\section{Vectors and matrices}

$c^{\prime} \quad$ Bidding price of GenCos.

$g^{\max ^{\prime}} \quad$ Bidding quantity of GenCos.

$g \quad$ Dispatched capacity of GenCos.

$\boldsymbol{d}$ Dispatched demand of retailers.

$\boldsymbol{d}^{\max } \quad$ Maximum demand of retailers.

[B] Susceptance matrix of the transmission system.

$\boldsymbol{v}$ Lagrange multiplier vector associated with the energy balance equation.

$\boldsymbol{u}_{1} \quad$ Lagrange multiplier vector associated with transmission lines inequity (thermal capacity limit). 
$\boldsymbol{u}_{2} \quad$ Lagrange multiplier vector associated with the production of generating units.

$\boldsymbol{u}_{3} \quad$ Lagrange multiplier vector associated with retailers consumption.

$\boldsymbol{v}^{\boldsymbol{c}} \quad$ Lagrange multiplier vector associated with the energy balance equation under competitive conditions.

$\boldsymbol{u}_{1}^{c} \quad$ Lagrange multiplier vector associated with transmission lines inequity (thermal capacity limit) under competitive conditions.

$\boldsymbol{u}_{2}^{\boldsymbol{c}} \quad$ Lagrange multiplier vector associated with the production of generating units under competitive conditions.

$\boldsymbol{u}_{3}^{c} \quad$ Lagrange multiplier vector associated with retailers consumption under competitive conditions.

$\boldsymbol{\theta}^{\boldsymbol{c}} \quad$ Node angle vector under competitive conditions.

$\boldsymbol{g}^{\boldsymbol{c}} \quad$ Dispatched capacity of GenCos under competitive conditions.

$\boldsymbol{d}^{c} \quad$ Dispatched demand of retailers under competitive conditions.

$\boldsymbol{x} \quad$ Vector variable representing TNSP's decision variables.

$\boldsymbol{y}_{\boldsymbol{i}} \quad$ Vector variable representing GenCo $i$ decision variables.

$\boldsymbol{y}_{-\boldsymbol{i}} \quad$ Vector variable representing decision variables of all GenCos except GenCo $i$.

Vector variable representing decision variables of MMC.

\section{INTRODUCTION}

M ARKET POWER of a producer is the ability to profitably maintain market prices above competitive levels for a significant period of time [1]. In economics, for a firm to have market power, the following two elements must be present.

1) First, the firm must have the ability to influence the market price by varying its own output.

2) Second, in doing so, the firm must be able to earn excess returns in the medium or long term [2].

A firm that has no influence over the market price is said to be a price taker and not deemed to have market power.

The exercise of market power in electricity market involves reducing output in order to raise the market price, and thereby earn even higher overall profit on the remaining output. This has the following effects.

1) The price-duration curve is higher than in the absence of the market power.

2) The market price reaches the price cap more frequently and load shedding occur more frequently than in the absence of market power.

Joskow and Schmalensee [3] showed numerically that transmission expansion reduces generators' market power. Wolfram [4] has examined empirically the bidding behavior of generators in England and Wales, including the impact of transmission constraints. Accordingly, he [4] reports that in England and
Wales generators protected by transmission constraints bid significantly higher than those without this status.

There have been various occasions in the Australian National Electricity Market (NEM) when a generator exercised market power because of constrained interconnectors. On February 4, 2003, an unplanned outage on the interconnector between the states of Victoria and South Australia reduced its capacity substantially. Consequently, a large generator in the South Australia region rebid $112 \mathrm{MW}$ of its capacity to prices greater than $\$ 9000$ [2].

Using a simplified version of the power network in California [5] has quantified the impact of local market power and transmission capacity. Bushnell [6] and Joskow and Tirole [7] show that generators benefit from a reduction in transmission capacity. Also, using a stylized version of the North America transmission system [8] highlights the effect of transmission capacity on encouraging competition among generating companies (GenCos).

Transmission capacity has been proved as an effective policy to reduce market power [9]-[11]. Leautier [11] suggests that policy maker can and should use transmission capacity for reducing market power in electricity markets.

In [12], no technical literature is cited on modeling of the market power in the mechanism of transmission expansion planning.

Leautier [10] sets up a framework for transmission planning based on the marginal value of transmission capacity. Despite of having a closed-form formulation, the mechanism cannot model the market power effect of transmission capacity. Shrestha and Fonseka [13] employ the same mathematical structure of [10], but used the congestion cost and congestion revenue as the driving signals for the need of network expansion. The proper level of congestion for a transmission network and the lack of modeling of market power effect of additional transmission capacity are two main shortcomings of the proposed framework. Lu et al. [14] suggest two heuristic procedures for transmission augmentation. The authors use unconstrained oligopoly equilibrium for the set of producers' bids, while the bids from the demand side are assumed as known from the analysis of the existing market data. Clearly, unconstrained oligopoly equilibrium cannot reflect the reality of the electricity market.

The TEAM methodology introduced by the California Independent System Operator (ISO) [15] can be acknowledged as a good model for economics-based transmission augmentation. However, it has two drawbacks. First, the strategic bidding of GenCos has been estimated through a tailor-made and empirical methodology that limits its application. Second, the whole framework does not have an integrated mathematical structure.

To model the market power effect of transmission capacity in the process of transmission augmentation, this paper proposes two closed-form mathematical structures. The mathematical structures are developed based on the concepts of quantity withheld and monopoly rent (MR) in economics. A metric termed $L$-shape area is developed and employed to model the quantity withheld concept. A numerical solution is developed to solve the mathematical structures. Section II deals with the 


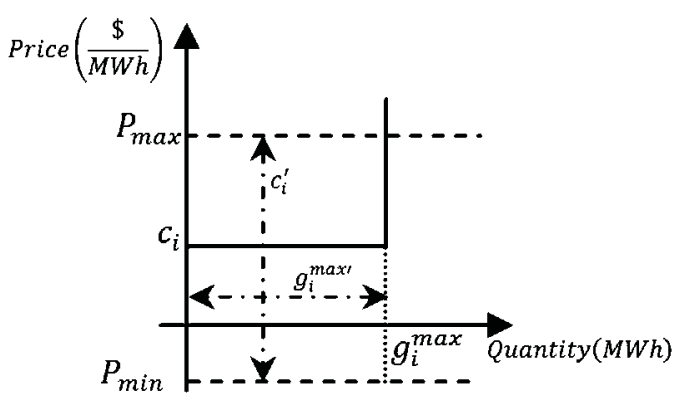

Fig. 1. Marginal cost curve and the biding strategy of a GenCo.

derivation of the mathematical structures. The developed numerical solution is detailed in Section III. Two case studies, the Garver's example system and the IEEE 14-bus example system, are employed and modified carefully to suit the needs of the calculations. The experimental results and discussions are collected in Section IV. Concluding remarks in Section V will close this paper.

\section{Building of the Mathematical StRUCture FOR TRANSMISSION SYSTEM AUGMENTATION}

Mathematical structures of the transmission augmentation considering the market power effect of transmission capacity are developed in three stages. In the first stage, we use the concepts of the simultaneous-move game and the Nash solution to model the electricity market operation. To derive a closed-form mathematical structure, the Nash equilibrium is reformulated as an optimization problem. In the second stage, the worst case Nash equilibrium is mathematically modeled based on two concepts of the MR and a developed metric termed the $L$-shape area. These two metrics are developed to model the effect of transmission capacity in reducing market power. In the third stage, the Stackelberg-Nash equilibrium concept is employed to derive the final mathematical structures. The developed structures can capture the effect of transmission capacity in reducing market power in their mechanisms of augmentation. We assume retailers to be competitive, and consequently, they do not behave strategically. Also, the study is for the worst-case scenario of the power system.

\section{A. Reformulation of the Nash Equilibrium Concept as the Zeros of M Function for Simulating of the Electricity Market}

Each GenCo offers a price-quantity pair $\left(c_{i}^{\prime}, g_{i}^{\max ^{\prime}}\right)$ to the market management company (MMC) to participate in the market. The marginal cost of a GenCo and its bidding strategy are shown in Fig. 1.

The $P_{\min }(\$)$ and $P_{\max }(\$)$ are the minimum and maximum limits on price offer of a GenCo. These limits are usually set by the electricity market regulator. The competition on price, the competition on quantity, and the competition on both price and quantity are economic structures established to model GenCos in an electricity market. This paper uses the price-quantity game to model GenCos.

Given the bidding strategies of other GenCo and TNSP's planning schedule revealed, each GenCo can find its op- timal strategy using the bilevel programming problem in the following:

$$
\begin{aligned}
& \operatorname{Max}_{c_{i}^{\prime}, g_{i}^{\max \prime}}\left[\left[v_{i} g_{i}-C\left(g_{i}\right)\right]\right] \\
& \text { s.t. } \\
& \begin{aligned}
P_{\min } \leq c_{i}^{\prime} \leq P_{\max } \\
o \leq g_{i}^{\max } \leq g_{i}^{\max } \\
\operatorname{Min}_{g, d, \theta, f_{i j}}\left[\sum_{i \in G} c_{i}^{\prime} g_{i}+\sum_{i \in D} \operatorname{VoLL}_{i}\left(d_{i}^{\max }-d_{i}\right)\right] \\
\text { s.t. } \\
\quad[\boldsymbol{B}] \boldsymbol{\theta}=\boldsymbol{g}-\boldsymbol{d} \quad \leftrightarrow \boldsymbol{v} \\
f_{i j}-\gamma_{i j}\left(n_{i j}^{0}+n_{i j}\right)\left(\theta_{i}-\theta_{j}\right)=0 \forall(i, j) \in L \\
\left|f_{i j}\right| \leq\left(n_{i j}^{0}+n_{i j}\right) f_{i j}^{\max } \forall(i, j) \in L \leftrightarrow u_{1} \\
\mathbf{0} \leq \boldsymbol{g} \leq \boldsymbol{g}^{\max } \quad \leftrightarrow \boldsymbol{u}_{\mathbf{2}} \\
\mathbf{0} \leq \boldsymbol{d} \leq \boldsymbol{d}^{\max } \quad \leftrightarrow \boldsymbol{u}_{\mathbf{3}}
\end{aligned}
\end{aligned}
$$

where $[B]$ is the nodal admittance matrix of the transmission system. $[\boldsymbol{B}]$ is a $N_{b} \times N_{b}$ matrix, with $N_{b}$ as the total number of buses in the system, $\theta$ is the vector of bus angles, $g$ and $d$ are the generation level of committed generators and the served demand of retailers, $f_{i j}$ is the MW flow between nodes $i$ and $j$, and $f_{i j}^{\max }$ is the maximum thermal capacity for the branch $i-j$. Also, $\gamma_{i j}$ is the susceptance of the branch $i-j, n_{i j}^{0}$ is the existing number of circuits, and $n_{i j}$ is the transmission network service provider (TNSP) decision variable on the number of new circuits. The variables $u$ and $v$ are the Lagrange multipliers of the associated constraints. The vector $v$ is the price of energy at different network connection points.

Using the Karush-Kuhn-Tucker optimality conditions, (1) can be generalized as

$$
\operatorname{Max}_{\substack{\boldsymbol{y}_{i} \in \boldsymbol{Y}_{i} \\ \boldsymbol{z} \in \boldsymbol{Z}}} f_{i}\left(\boldsymbol{x}, \boldsymbol{y}_{i}, \boldsymbol{y}_{-i}, \boldsymbol{Z}\right)
$$

where $f_{i}$ is the profit of GenCo $i, x=n$ is the TNSP decision vector, $y_{i}=\left(c_{i}^{\prime}, g_{i}^{\max ^{\prime}}\right)$ is the action vector of the $i$ th GenCO, and $y_{-i}=\left(y_{1}, \ldots, y_{i-1}, y_{i+1}, \ldots, y_{m}\right)$, with $m$ as the total number of GenCos. The vector $\boldsymbol{z}=(\boldsymbol{g}, \boldsymbol{d}, \boldsymbol{\theta}, \boldsymbol{u}, \boldsymbol{v})$ and $\mathbf{z}$ vector is constrained by the set of $\mathbf{Z}$, which is the set defined by the constraints of the inner optimization problem in (1). The elements of vector $\boldsymbol{z}$ are the dispatched generation capacity, the dispatched demand, the bus angle, and the Lagrange multipliers as defined in (1).

Since all GenCos are of equal status, they must reveal their strategies simultaneously. Hence, for all GenCos, a popular solution concept is the Nash equilibrium.

The Nash equilibrium problem can be formulated as the problem of finding the zeros of a function $M$, which is defined in (3).

Definition 1: Let $Y$ be a nonempty set that defines the strategy space of all GenCos participating in the electricity market. The function $M(y): Y \rightarrow R^{+}$is defined as follows:

$$
M(\mathbf{y})=\sum_{i=1}^{m}\left[\operatorname{Max}_{\substack{\boldsymbol{y} \in \boldsymbol{i} \in \boldsymbol{Y}_{\boldsymbol{i}} \\ \boldsymbol{z}}} f_{i}\left(\boldsymbol{x}, \boldsymbol{y}_{i}, \boldsymbol{y}_{-\boldsymbol{i}}, \boldsymbol{z}\right)-f_{i}(\boldsymbol{x}, \boldsymbol{y}, \boldsymbol{z})\right] .
$$

The following theorem can be derived consequently. 
Theorem 1: The function $M(y): \boldsymbol{Y} \rightarrow R^{+}$is real and nonnegative on $\mathbf{Y}$. Also, Nash equilibria are the zeros of $M$.

Proof: See Appendix A.

Having (3) as the alternative formulation of Nash equilibria, the mathematical framework of the competition among GenCos can be built as

$$
\begin{aligned}
& \operatorname{Min}_{\boldsymbol{c}^{\prime}, \boldsymbol{g}^{\max }} \sum_{i=1}^{m}\left[\operatorname{Max}_{\substack{\boldsymbol{y}_{\boldsymbol{i}} \in \boldsymbol{Y}_{\boldsymbol{i}} \\
\boldsymbol{z} \in \boldsymbol{Z}}} f_{i}\left(\boldsymbol{x}, \boldsymbol{y}_{\boldsymbol{i}}, \boldsymbol{y}_{-\boldsymbol{i}}, \boldsymbol{z}\right)-\left[v_{i} g_{i}-C\left(g_{i}\right)\right]\right] \\
& \text { s.t. } \\
& \boldsymbol{P}_{\min } \leq \boldsymbol{c}^{\prime} \leq \boldsymbol{P}_{\max } \\
& o \leq \boldsymbol{g}^{\max \prime} \leq \boldsymbol{g}^{\max } \\
& \operatorname{Min}_{\boldsymbol{g}, \boldsymbol{d}, \boldsymbol{\theta}, f_{i j}}\left[\sum_{i \in G} c_{i}^{\prime} g_{i}+\sum_{i \in D} \operatorname{VoLL}_{i}\left(d_{i}^{\max }-d_{i}\right)\right] \\
& \text { s.t. } \\
& \begin{array}{l}
{[\boldsymbol{B}] \boldsymbol{\theta}=\boldsymbol{g}-\boldsymbol{d} \quad \leftrightarrow \boldsymbol{v}} \\
f_{i j}-\gamma_{i j}\left(n_{i j}^{0}+n_{i j}\right)\left(\theta_{i}-\theta_{j}\right)=0 \forall(i, j) \in L \\
\left|f_{i j}\right| \leq\left(n_{i j}^{0}+n_{i j}\right) f_{i j}^{\max } \forall(i, j) \in L \leftrightarrow u_{1} \\
\mathbf{0} \leq \boldsymbol{g} \leq \boldsymbol{g}^{\max } \quad \leftrightarrow \boldsymbol{u}_{\mathbf{2}} \\
\mathbf{0} \leq \boldsymbol{d} \leq \boldsymbol{d}^{\max } \quad \leftrightarrow \boldsymbol{u}_{\mathbf{3}} .
\end{array}
\end{aligned}
$$

If an array $y=\left(y_{1}, \ldots, y_{i}, \ldots, y_{m}\right)$ satisfies $M\left(y_{1}, \ldots, y_{i}, \ldots, y_{m}\right)=0$, then $\boldsymbol{y}$ must be a solution of (4), and consequently, a Nash equilibrium of the game. The set of all optimal solutions of (3) is the Nash equilibria of the price-quantity game among GenCos. If (3) does not have any optimal solution, there is no Nash equilibrium of GenCos in the given bilevel programming problem.

The set of Nash equilibria of the price-quantity game can be found by solving the optimization problem formulated in (4).

An average method to deal with many Nash equilibria of the quantity game among GenCos was used in [16]. This methodology calculates the situation of the market under each Nash equilibrium. Then after, the method takes an average for each of variables of interest in the process of transmission augmentation. The problem with this method is that, in some cases, the average of interested variable approaches zero and cannot provide any valuable information to the process of transmission augmentation.

This paper uses the worst Nash equilibrium in terms of MR or a developed metric termed $L$-shape area metric $\left(A_{L}\right)$ for simulating the electricity market. The MR and the $A_{L}$ are used for measuring market power.

The mathematical formulations of the worst Nash equilibrium in terms of $\mathrm{MR}$ and the $A_{L}$ are formulated as follows:

$$
\begin{aligned}
& \operatorname{Max}_{\boldsymbol{c}^{\prime}, \boldsymbol{g}_{\max \prime}}[\mathrm{MR}] \\
& \operatorname{Max}_{\boldsymbol{c}^{\prime}, \boldsymbol{g}^{\max \prime}}\left[A_{L}\right] .
\end{aligned}
$$

By doing this, the worst equilibrium of the market is used in transmission augmentation as a signal that is always available.

\section{B. Measuring Market Power-Application of the Quantity Withheld and MR Concepts}

The introduction of competitive markets aims to reduce prices, improve the quality of services, and on a long-term basis make the market more efficient [17]. Providing an environment for perfect competition between generators on one side of market and between retailers on the other side is the necessary condition in achieving the aforementioned targets.

The conditions required for perfect competition are [18]:

1) a large number of generators producing the same product;

2) each generator attempts to maximize its payoff;

3) each generator is a price taker;

4) generators have exact knowledge of all parameters of significance to their decisions; and

5) transmission is costless.

The first condition aims to prevent the formation of market concentration in terms of Herfindahl-Hirshman index and pivotal generators in terms of residual supply index [19]. Having rational generators is the immediate consequence of second condition [20]. It can be mathematically shown that a rational generator requires bidding its marginal cost, assuming that the generator is a price taker, to maximize its profit [21]. Condition 4) addresses that the generators must have perfect information. Finally, the last condition addresses bottlenecks in the highvoltage transmission systems. Bottlenecks are one of the major issues in market separation. Arguably, none of these conditions ever exists in a real electricity market. Accordingly, the real electricity market has deviation from the competitive electricity market.

GenCos can exercise market power in two ways, namely, financial withholding and physical withholding. Financial withholding means bidding excessively above the marginal cost of production and driving up the price. Physical withholding is when a GenCo withholds some of its available capacity from the market, thus reducing effective supply and driving up the price it receives for the rest of its portfolio [19].

The MR is economically defined as the extra return that GenCos receive from the electricity market as a result of exercising market power [22].

The market power can be measured based on its consequences on the electricity market. Section II-B1 measures market power through a developed metric termed $L$-shape area. The $L$-shape area is designed to model two forms of financial withholding and physical withholding in a single metric. Section II-B2 measures the market power based on the MR consequence of the market power.

1) Design of the $A_{L}$ for Measuring Market Power-Application of the Quantity Withheld Concept: The $A_{L}$ is designed based on measuring the deviation of the electricity market equilibrium from the competitive equilibrium of the electricity market.

Definition of $A_{L}$ : Let $v_{c}$ and $v$ be the nonempty vectors in $R^{n}$ representing nodal prices (in $\$ / \mathrm{MWh}$ ), and let $G_{\max } \neq 0$ and $G \neq 0$ be the aggregated offered capacity of GenCos (in $\mathrm{MWh}$ ) in the following two scenarios:

1) competitive electricity market with relaxed transmission constraints; and

2) actual electricity market.

If $\Delta v$ is the Euclidean norm of the vector $v_{c}-v$ as in

$$
\Delta v=\left\|\boldsymbol{v}-\boldsymbol{v}_{\boldsymbol{c}}\right\|_{2}
$$




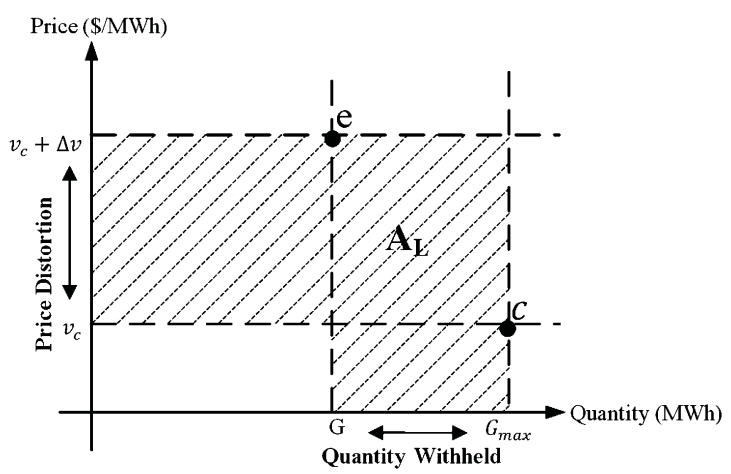

Fig. 2. $L$-shape area metric.

then $A_{L} \geq 0$ (in $\left.\$ / h\right)$ is

$$
A_{L}=G_{\max }\left(v_{c}+\Delta v\right)-G v_{c}
$$

where $A_{L}$ is depicted in Fig. 2.

The variable $\Delta v$ is the price distortion of the electricity market, $\Delta$ Price $_{\text {Distortion, and }} G_{\max }-G$ is the quantity withheld, $\Delta$ Quantity ${ }_{\text {Distortion }}$.

Based on the $A_{L}$ criterion and having the profitability assumed, the following theorem can be developed.

Theorem 2: Let point $c$ shown in Fig. 2 represent the competitive equilibrium of the electricity market. Also, let point $e$ shown in Fig. 2 represent the actual equilibrium of the electricity market. The necessary and sufficient condition for perfect competition in the electricity market is that

$$
A_{L}=0
$$

Proof: See Appendix B.

In this paper, we approximate the competitive equilibrium of the electricity market with the one with relaxed transmission constraints. This reduces the complexity of the associated mathematical structure for modeling market power in the introduced mechanism of the transmission augmentation. Although this calculation is in line with [23]-[25], but further research can be carried out to remove this assumption. One possible approach to proceed is to find the $A_{L}$ metric for each node of the system.

2) MR Metric for Measuring Market Power: Consumers are likely to be harmed by the strategic behaviors of GenCos. It is likely that all consumers will face higher prices if some GenCos bid strategically. Similarly, some GenCos will have higher profits under strategic bidding than they would if all GenCos bid their marginal cost curve.

$\mathrm{MR}$ is the consequence of exercising market power by GenCos. It is defined as the excess profit that GenCos capture under strategic bidding behaviors.

Mathematically, the MR can be calculated as

$$
\mathrm{MR}=\sum_{i=1}^{N_{G}} \pi_{i}-\pi_{i}^{c}
$$

where $\pi_{\mathrm{i}}$ is the profit of the $i$ th GenCo in the electricity market and $\pi_{i}^{c}$ is the profit of the same GenCo in the competitive electricity market.

\section{Mathematical Structure of the TNSP Augmentation Mechanism}

The proposed mathematical structures for transmission system augmentation based on the developed metrics of quantity withheld $A_{L}$ or MR, and also the introduced $M$ function are presented in (11) and (12), respectively. Both mathematical structures can reduce market power in the electricity market through their assessment mechanisms of transmission system augmentation.

In the structures (11) and (12), $c_{i j}$ is the transmission investment cost between nodes $i$ and $j, n_{i j}$ is an integer number, which represents the new circuits in the corridor $i-j$ with a maximum number of $n_{i j}^{\max }, g_{i}^{c}$ is the competitive dispatch of the GenCo $i$, and $d_{i}^{c}$ is the competitive dispatch of retailer $i$. The MR is the monopoly rent as introduced previously

$$
\begin{aligned}
& \operatorname{Min}_{n_{i j}} \Gamma=\left[\left[\sum_{(i, j) \in L} c_{i j} n_{i j}+\operatorname{Max}_{c^{\prime}, g^{\max \prime}}\left[A_{L}\right]\right]\right] \\
& \text { s.t. } \\
& \begin{aligned}
0 \leq n_{i j} \leq n_{i j}^{\max } \forall(i, j) \in L, n_{i j} \in \mathbb{N} \\
\operatorname{Min}_{c^{\prime}, g^{\max }} \sum_{i=1}^{m}\left[\operatorname{Max}_{\substack{y_{i} \in Y_{i} \\
z \in Z}} f_{i}\left(x, y_{i}, y_{-i}, z\right)\right. \\
\left.-\left[v_{i} g_{i}-C\left(g_{i}\right)\right]\right]
\end{aligned}
\end{aligned}
$$

s.t.

$$
\begin{aligned}
& P_{\min } \leq c^{\prime} \leq P_{\max } \\
& o \leq g^{\max \prime} \leq g^{\max } \\
& \operatorname{Min}_{g, d, \theta, f_{i j}}\left[\sum_{i \in G} c_{i}^{\prime} g_{i}+\sum_{i \in D} \operatorname{VoLL}_{i}\left(d_{i}^{\max }-d_{i}\right)\right] \\
& \text { s.t. } \\
& \quad[B] \theta=g-d \quad \leftrightarrow v \\
& \quad f_{i j}-\gamma_{i j}\left(n_{i j}^{0}+n_{i j}\right)\left(\theta_{i}-\theta_{j}\right)=0 \forall(i, j) \in L \\
& \left|f_{i j}\right| \leq\left(n_{i j}^{0}+n_{i j}\right) f_{i j}^{\max } \forall(i, j) \in L \leftrightarrow u_{1} \\
& 0 \leq g \leq g^{\max } \quad \leftrightarrow u_{2} \\
& 0 \leq d \leq d^{\max } \quad \leftrightarrow u_{3}
\end{aligned}
$$$$
\operatorname{Min}_{n_{i j}} \Gamma=\left[\left[\sum_{(i, j) \in L} c_{i j} n_{i j}\right.\right.
$$$$
+\left\{\left[\sum_{i \in G} c_{i} g_{i}^{c}+\sum_{i \in D} \operatorname{VoLL}_{i}\left(d_{i}^{\max }-d_{i}^{c}\right)\right]\right.
$$

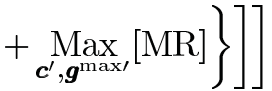

s.t.

$$
\begin{aligned}
0 \leq n_{i j} \leq n_{i j}^{\max } \forall(i, j) \in L, n_{i j} \in \mathbb{N} \\
\operatorname{Min}_{\boldsymbol{c}^{\prime}, \boldsymbol{g}^{\max \prime}} \sum_{i=1}^{m}\left[\operatorname{Max}_{\substack{\boldsymbol{y}_{\boldsymbol{i}} \in \boldsymbol{Y}_{\boldsymbol{i}} \\
\boldsymbol{z} \in \boldsymbol{z}}} f_{i}\left(\boldsymbol{x}, \boldsymbol{y}_{\boldsymbol{i}}, \boldsymbol{y}_{-\boldsymbol{i}}, \boldsymbol{z}\right)\right. \\
\left.-\left[v_{i} g_{i}-C\left(g_{i}\right)\right]\right]
\end{aligned}
$$

s.t. 


$$
\begin{aligned}
& \boldsymbol{P}_{\min } \leq \boldsymbol{c}^{\prime} \leq \boldsymbol{P}_{\max } \\
& o \leq \boldsymbol{g}^{\max \prime} \leq \boldsymbol{g}^{\max } \\
& \operatorname{Min}_{\boldsymbol{g}, \boldsymbol{d}, \boldsymbol{\theta}, f_{i j}}\left[\sum_{i \in G} c_{i}^{\prime} g_{i}+\sum_{i \in D} \operatorname{VoLL}_{i}\left(d_{i}^{\max }-d_{i}\right)\right] \\
& \text { s.t. } \\
& {[B] \boldsymbol{\theta}=\boldsymbol{g}-\boldsymbol{d} \quad \leftrightarrow \boldsymbol{v}} \\
& f_{i j}-\gamma_{i j}\left(n_{i j}^{0}+n_{i j}\right)\left(\theta_{i}-\theta_{j}\right)=0 \forall(i, j) \in L \\
& \left|f_{i j}\right| \leq\left(n_{i j}^{0}+n_{i j}\right) f_{i j}^{\max } \forall(i, j) \in L \leftrightarrow u_{1} \\
& \mathbf{0} \leq \boldsymbol{g} \leq \boldsymbol{g}^{\max \prime} \quad \leftrightarrow \boldsymbol{u}_{\mathbf{2}} \\
& \mathbf{0} \leq \boldsymbol{d} \leq \boldsymbol{d}^{\max } \leftrightarrow \boldsymbol{u}_{\mathbf{3}} \\
& \operatorname{Min}_{\boldsymbol{g}^{\boldsymbol{c}}, \boldsymbol{d}^{\boldsymbol{c}}, \boldsymbol{\theta}^{\boldsymbol{c}}, f_{i j}^{c}}\left[\sum_{i \in G} c_{i} g_{i}^{c}+\sum_{i \in D} \operatorname{VoLL}_{i}\left(d_{i}^{\max }-d_{i}^{c}\right)\right] \\
& \text { s.t. } \\
& {[B] \theta^{c}=g^{c}-d^{c} \quad \leftrightarrow v^{c}} \\
& f_{i j}^{c}-\gamma_{i j}\left(n_{i j}^{0}+n_{i j}\right)\left(\theta_{i}^{c}-\theta_{j}^{c}\right)=0 \forall(i, j) \in L \\
& \left|f_{i j}^{c}\right| \leq\left(n_{i j}^{0}+n_{i j}\right) f_{i j}^{\max } \forall(i, j) \in L \leftrightarrow u_{1}^{c} \\
& \mathbf{0} \leq \boldsymbol{g}^{\boldsymbol{c}} \leq \boldsymbol{g}^{\max } \leftrightarrow \boldsymbol{u}_{\mathbf{2}}^{\boldsymbol{c}} \\
& 0 \leq \boldsymbol{d}^{c} \leq \boldsymbol{g}^{\max } \leftrightarrow \boldsymbol{u}_{3}^{c} .
\end{aligned}
$$

The minimization problem, $\operatorname{Min}_{g^{c}, d^{c}, \theta^{c}, f i j^{c}}$, is the securityconstraint economic dispatch under competitive equilibrium of the electricity market. Dispatch results of the competitive equilibrium of the electricity market, denoted by letter " $c$ " as the superscript in (12), are used for calculating the GenCos' profit in the competitive equilibrium of the electricity market. Also, the effect of transmission capacity on the efficiency of the electricity

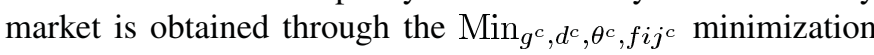
problem. The objective of this minimization problem is the total cost to the society at the competitive equilibrium of the electricity market and termed competitive social cost. Accordingly, the TNSP objective function in (12), $\Gamma$, has three components: the transmission investment cost, the competitive social cost, and the MR. The competitive social cost is used to measure the impact of transmission capacity on the efficiency of the dispatch and the MR as a metric of the market power exercised by GenCos.

Comparing the mathematical structure introduced in (11) with the one introduced in (12) can clearly show that introducing the $A_{L}$ metric has reduced the mathematical structure from a three-level structure to a two-level structure.

The transmission planning schedule found based on the structure (11) or (12) is developed for the highest forecast demand in the horizon year of planning. The coefficient $\sigma$ is the duration of this load scenario in hours.

In developing of the mathematical structures (11) and (12), a single scenario of the electricity market is considered. The most likely scenario of the electricity market for the sake of this paper study can be found using the "importance sampling technique" reported in [15]. This helps to make the contributions of the paper clear without making it cloudy with the uncertainties involved in the decision-making process. However, the extension of the proposed structures to include the uncertainties can be addressed in future research works.

\section{DESIGNED NumericAl SOLUTION}

Generally, optimization algorithms can be categorized in two classes: deterministic and stochastic algorithms [26], [27]. State-space search, branch and bound, and algebraic geometry are samples of the deterministic approaches. The Monte Carlo algorithm, evolutionary computation, and swarm intelligence are classified under the stochastic algorithms. Because of the complexity of the developed structures in (10) and (11), which stems from the nested optimization and the high dimensionality of the search space, deterministic approaches cannot lead to promising results. To reduce the complexity of the developed structures and make it more suitable for stochastic optimization approaches, the price-quantity pairs offered by GenCos are approximated by discrete variables. Then after, a stochastic optimization algorithm is designed to find a near-optimum solution of the developed structures.

The developed optimization algorithm is a standard genetic algorithm (GA) nested with an island parallel genetic algorithm (IPGA). The GA deals with the TNSP decision variables, and the IPGA deals with the decision variables of the electricity market operation. The steps of the developed numerical solutions are as follows.

Step 1) Input power system and electricity market data, and set the generation number to 1 .

Step 2) Initialize the TNSP parent population randomly.

Step 3) Go to IPGA module and find the worst $A_{L}$ or MR associated with each of transmission planning schedules in the parent population.

Step 4) Increase the generation number by 1 .

Step 5) Produce the offspring population through the selection, crossover, and mutation operators of GA from the parent population.

Step 6) Go to IPGA module and find the worst $A_{L}$ or MR associated with each of transmission planning schedules in the offspring population.

Step 7) Rank transmission planning schedules in the TNSP population using the following Pareto ranking technique [28].

Step 7.1) Set $i=1$.

Step 7.2) Identify nondominated solutions in the TNSP population and assign them to rank $i$.

Step 7.3) Set $i=i+1$.

Step 7.4) Exclude the rank $i$ solutions from the TNSP population.

Step 7.5) If all of the TNSP solutions are ranked go to step 7.6 else go to step 7.2.

Step 7.6) End.

1) Update the parent population by the best TNSP's designs.

2) If the generation number is greater than maximum number of generations, then go to step 10; else go to step 4 .

3) Display the TNSP's designs of the last generation with rank one as the best-found transmission planning schedule.

An IPGA is embedded in the GA for solving the multimodal optimization problem introduced by the $M$ function. The techniques developed for solving problems of this type falls into three broad categories [29].

1) Iterative methods [30], [31]: 

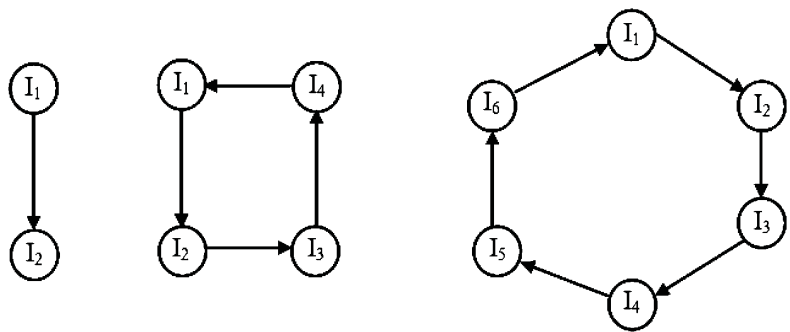

Fig. 3. Typical communication topology for hybrid bilevel GA/IPGA.

Iterative methods address the problem of locating multiple optimal of a multimodal function by repeatedly applying the same optimization algorithm. To prevent repeated convergence to the same solution, iterative methods use various techniques to prohibit the underlying optimization method from exploring the already explored areas.

2) Fitness sharing [32], [33]:

The idea of sharing comes from an analogy with nature. In natural ecosystems, there are many different ways in which species may survive and form different roles. Each role is an ecological niche. The analogy in function optimization is that the location of each optimum represents a niche, and by suitably sharing the fitness associated with each niche, we can encourage the formation of stable subpopulations at each optimum.

3) Parallel islands [34]:

This method tries to produce multiple solutions to a multimodal optimization problem by forming populations that evolve in parallel. The method of parallel islands uses some communication topology to allow good characteristics of individuals to be spread.

Unlike the iterative methods and fitness sharing methods, the initial implementation of the parallel islands method has shown very promising results in solving the multimodal optimization problem introduced by the $M$ function. Hence, the IPGA has been designed based on the concept of the communicative parallel islands.

The island model will consider $N$ islands $\left\{I_{1}, I_{2}, \ldots, I_{N}\right\}$, each of them with $S$ chromosomes. They evolve separately with a specific communication topology. The island method causes diversification among individuals and removes the pressure of the already found optima from other individuals.

Given $\mathrm{N}$ islands, the next decision is the subpopulation interconnection. This generally referred to as the communication topology in which the islands accept or send migrants from or to other islands. The $N$ islands $\left\{I_{1}, I_{2}, \ldots, I_{N}\right\}$ are considered to be the vertices of a graph with each edge specifying a communication link between the incident vertices. In our developed numerical solution, the communication topology is considered to be static. Fig. 3 shows some typical communication topologies.

Given the ability of two islands to communicate, the magnitude and frequency of the communication must be determined. The migration pattern is important to the overall evolutionary process. The connectivity of the communication topology, the magnitude of the communication, and the frequency of the communication are the very important factors of the migration operator. These parameters determine the amount of isolation and interaction among the subpopulations.

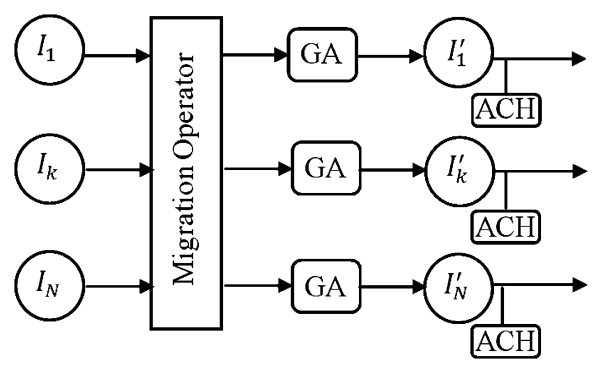

Fig. 4. One iteration of IPGA.

After employing the migration operator, the islands will evolve for a specific number of times through the crossover and mutation operators of the GAs. At this stage, the set of $\left\{I_{1}^{\prime}, I_{2}^{\prime}, \ldots, I_{N}^{\prime}\right\}$ are formed. Each of the evolved islands, $\left\{I_{1}^{\prime}, I_{2}^{\prime}, \ldots, I_{N}^{\prime}\right\}$, will be checked for any zero of the $M$ function. If any island has converged to zero(s) of the $M$ function, the zeros will be compared to an archive list and the new ones will be added to the archive.

Fig. 4 shows an iteration of the IPGA module based on the migration operator.

The IPGA module starts with the initialization of the islands 1 to $N$. Then these islands communicate with each other using the communication topology and the migration pattern. This is done through the migration operator. At this stage, each island evolves in isolation employing the standard GA to get the evolved islands $I_{1}^{\prime}$ to $I_{N}^{\prime}$. The evolved island will be checked and new zeros of the $M$ function will be archived, the ACH box shown in Fig. 4.

The IPGA terminates the iterations based on the one of the following stop criteria:

1) total number of iterations is greater than the maximum number of iterations; or

2) the algorithm has not found any new zero of the $M$ function for the last few iterations.

The developed IPGA can effectively locate the set of Nash equilibria of the electricity market. Then after, the worst Nash equilibrium can be found by calculating the MR metric or the $A_{L}$ under different equilibriums of the electricity market using linear programming.

\section{EXPERIMENTAL RESULTS AND DISCUSSIONS}

Two example systems are selected and analyzed. The concept of the designed structures is explained by a thorough economic study of the modified Garver's example system. The IEEE 14-bus example system is modified and employed to show the whole process of transmission system augmentation including the mechanism and the developed numerical solution. Both example systems are designed carefully to suit the needs of the economic studies. Throughout the economic study, we compare the optimal policies of the TNSP obtained by the derived mathematical structures in (11) and (12) with each other. Also, the optimal policy of the TNSP without considering market power is compared with the mathematical structures in (11) and (12). The software code is written in Fortran language using the International Mathematical and Statistical Library (IMSL). The 
TABLE I

GENERATORS' DATA

\begin{tabular}{c|c|c}
\hline Generator & $\begin{array}{c}\text { Generating } \\
\text { capacity } \\
\text { (MW) }\end{array}$ & $\mathrm{c}(\$ / \mathrm{MW})$ \\
\hline GenCo1 & 220 & 12 \\
\hline GenCo2 & 460 & 20 \\
\hline GenCo3 & 600 & 35 \\
\hline Total & 1280 & \\
\hline
\end{tabular}

TABLE II

RETAILERS' DATA

\begin{tabular}{c|c|c}
\hline Retailer & $\begin{array}{c}\text { Demand } \\
(\mathrm{MW})\end{array}$ & VoLL (\$/MW) \\
\hline R1 & 80 & 20,000 \\
\hline R2 & 130 & 40,000 \\
\hline R3 & 40 & 10,000 \\
\hline R4 & 160 & 30,000 \\
\hline R5 & 115 & 50,000 \\
\hline Total & 525 & \\
\hline
\end{tabular}

TABLE III

TRANSMISSION NETWORK DATA

\begin{tabular}{c|c|c|c|c}
\hline Line\# & From & To & Reactance (Ohm) & Limit (MW) \\
\hline 1 & Bus1 & Bus2 & 0.004 & 40 \\
\hline 2 & Bus1 & Bus4 & 0.006 & 50 \\
\hline 3 & Bus1 & Bus5 & 0.002 & 60 \\
\hline 4 & Bus2 & Bus3 & 0.002 & 180 \\
\hline 5 & Bus2 & Bus4 & 0.004 & 50 \\
\hline 6 & Bus2 & Bus6 & 0.003 & 40 \\
\hline 7 & Bus3 & Bus5 & 0.002 & 160 \\
\hline 8 & Bus4 & Bus6 & 0.003 & 100 \\
\hline
\end{tabular}

TABLE IV

Transmission NETWORK AUgMENTATION DATA

\begin{tabular}{c|c|c|c|c|c}
\hline Line\# & From & To & $\begin{array}{c}\text { Max. } \\
\text { number } \\
\text { of } \\
\text { Circuits } \\
(\mathrm{Ckt})\end{array}$ & $\begin{array}{c}\text { Capacity } \\
\text { (MW/Ckt) }\end{array}$ & $\begin{array}{c}\text { Transmission } \\
\text { Investment cost } \\
(\$ / C k t)\end{array}$ \\
\hline 1 & Bus1 & Bus2 & 2 & 120 & 850,000 \\
\hline 2 & Bus1 & Bus4 & 2 & 180 & 500,000 \\
\hline 3 & Bus2 & Bus3 & 2 & 150 & 700,000 \\
\hline 4 & Bus2 & Bus6 & 2 & 120 & 550,000 \\
\hline 5 & Bus3 & Bus4 & 2 & 150 & 600,000 \\
\hline 6 & Bus3 & Bus5 & 2 & 160 & 100,000 \\
\hline 7 & Bus4 & Bus6 & 2 & 160 & 540,000 \\
\hline 8 & Bus5 & Bus6 & 2 & 140 & 120,000 \\
\hline
\end{tabular}

developed code is solved on a double-core, $3.0-\mathrm{GHz}$, Pentium-4 PC.

\section{A. Modified Garver's Example System}

For conceptual evaluation of the developed structures, a modified Garver's six-bus example system has been tested.

The Garver's example system has been modified to a network with six buses and eight transmission lines. The data of the system are presented in Tables I-IV.

The single line diagram of the example system is shown in Fig. 5.

Each GenCo has ten strategies to participate in the energy market. These strategies are built up by fixing the price at the

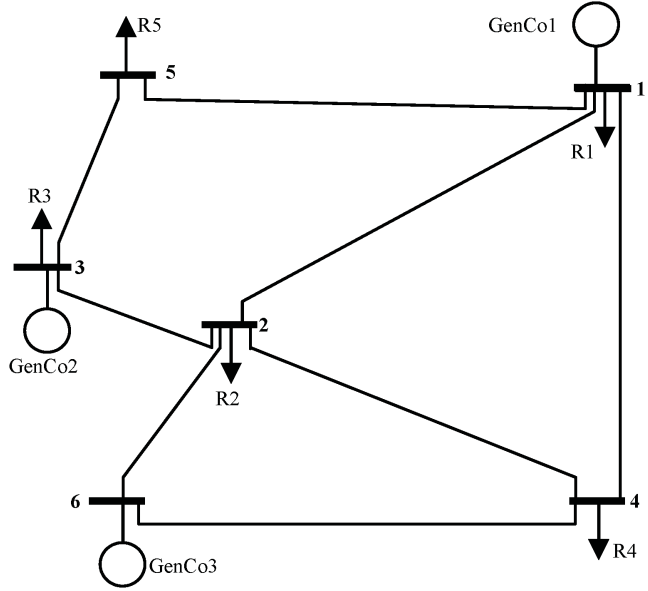

Fig. 5. Modified Garver's example system.

marginal cost and varying the quantity from $10 \%$ of generation capacity to total capacity in steps of $10 \%$.

Section IV-B accommodates an economic study on market power under the scenario in which the transmission system is augmented by the $A_{L}$ and also the MR metric.

\section{B. Economic Study on Market Power Under the Scenarios in Which the Transmission System is Augmented by the $A_{L}$ and the MR Metric}

The approximate competitive equilibrium of the electricity market is located at (1280 MW, $20 \$ / \mathrm{MWh})$. The equilibrium of the electricity market in the status quo transmission system is at (432 MW, 15067 \$/MWh). The GenCos reduce their capacity by $848 \mathrm{MW}$ and this raises the market price from $20 \$ / \mathrm{MWh}$ to $15067 \$ / \mathrm{MWh}$. This is equivalent to $A_{L}=47257900 \$ / \mathrm{h}$. The high order of $A_{L}$ shows the high sensitivity of the market price to the generators capacity. This can be expected for the current case study as a result of limited number of GenCos.

Fig. 6 shows different planning schedules of the TNSP ranked based on the cost of transmission planning schedule and the $A_{L}$ metric.

Since $A_{L}$ is the deviation from the approximate competitive equilibrium, the lower rank presents the better situation of the electricity market in terms of market power. The pareto optimal set of the TNSP solutions, the pareto front, and the strength of each solution are shown in Fig. 6. The strength of pareto optimal solutions or the TNSP revenue cap can be employed for ranking the pareto optimal set of the TNSP solutions. This section uses $\$ 1500000$ as the TNSP revenue cap for its economic study. Given this, the TNSP solution with strength of 221/257 will be selected. This TNSP solution dominates 221 solutions of the total 257 solutions of the TNSP. The vector $n_{A L}=(0,1,0,0,0,1,1,0)$ shows the number of circuits in each corridor of Table IV. Line number in Table IV is the element number of the vector $n_{A L}$. Considering the selected optimum transmission planning schedule for the TNSP, the bid-based security-constrained economic dispatch results for the equilibrium of the electricity market in status quo transmission system and in augmented transmission system are collected in Tables V-VIII. 


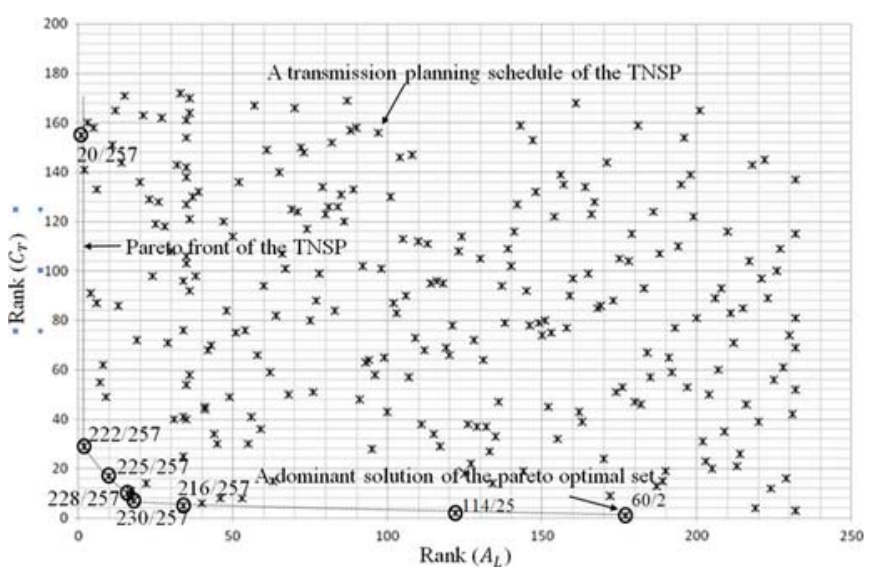

Fig. 6. Pareto front of the TNSP transmission planning schedules based on the proposed $A_{L}$ metric and the transmission investment cost.

TABLE V

ECONOMIC DISPATCH RESULTS IN THE EQUILIBRIUM OF THE ELECTRICITY MARKET IN STATUS QUO TRANSMISSION SYSTEM

\begin{tabular}{|c|c|c|c|c|}
\hline $\begin{array}{l}\text { Bus } \\
\text { No. }\end{array}$ & Voltage Angle (radian) & $\begin{array}{c}\text { Generation } \\
\text { (MW) }\end{array}$ & $\begin{array}{c}\text { Load } \\
(\mathrm{MW})\end{array}$ & $\begin{array}{c}P^{*} \\
(\$ / M W h) \\
\end{array}$ \\
\hline 1 & 0.00 & 220.00 & 73.33 & 20,000 \\
\hline 2 & -0.16 & 0.00 & 106.00 & 40,000 \\
\hline 3 & -0.05 & 92.00 & 0.00 & 45,000 \\
\hline 4 & -0.28 & 0.00 & 156.67 & 30,000 \\
\hline 5 & -0.12 & 0.00 & 96.00 & 50,000 \\
\hline 6 & -0.04 & 120.00 & 0.00 & 27,500 \\
\hline \multicolumn{2}{|r|}{ Total/Installed } & $432 / 432$ & $432 / 525$ & \\
\hline Aver & of Nodal Prices $(\$ / M W h)$ & \multicolumn{3}{|c|}{35,416} \\
\hline
\end{tabular}

TABLE VI

POWER Flows OF THE TRANSMISSION LINES IN THE EQUILIBRIUM OF THE ELECTRICITY MARKET IN STATUS QUO TRANSMISSION SYSTEM

\begin{tabular}{l|c|c|c}
\hline From & To & Power Flow (MW) & Capacity (MW) \\
\hline Bus1 & Bus2 & 40.00 (Congested) & 40.00 \\
\hline Bus1 & Bus4 & 46.67 & 50.00 \\
\hline Bus1 & Bus5 & 60.00 (Congested) & 60.00 \\
\hline Bus2 & Bus3 & -56.00 & 180.00 \\
\hline Bus2 & Bus4 & 30.00 & 50.00 \\
\hline Bus2 & Bus6 & -40.00 (Congested) & 40.00 \\
\hline Bus3 & Bus5 & 36.00 & 160.00 \\
\hline Bus4 & Bus6 & -80.00 & 100.00 \\
\hline
\end{tabular}

Table IX compares the market power metrics of financial withholding, physical withholding, and the proposed $A_{L}$ metric in two scenarios of the status quo transmission system and the augmented transmission system. The overall profit of GenCos is calculated in the last row of Table IX.

As in Table IX, the transmission planning schedule $n_{A L}$ has decreased the market power in terms of financial withholding by $46 \%$. This is measured by price distortion metric,

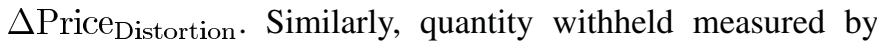
$\Delta$ Quantity $_{\text {Distortion }}$ has reduced by $6 \%$, which is an improvement in overall physical withholding.

The decrease of financial and physical withholding of the electricity market and a reduction of $19 \%$ in overall profit of GenCos can be understood as the market power reduction as the
TABLE VII

ECONOMIC DISPATCH RESULTS IN THE EQUILIBRIUM OF THE ELECTRICITY MARKET IN AUGMENTED TRANSMISSION SYSTEM

\begin{tabular}{|c|c|c|c|c|}
\hline $\begin{array}{l}\text { Bus } \\
\text { No. }\end{array}$ & $\begin{array}{c}\text { Voltage Angle } \\
\text { (radian) }\end{array}$ & $\begin{array}{c}\text { Generation } \\
\text { (MW) }\end{array}$ & $\begin{array}{c}\text { Load } \\
(\mathrm{MW}) \\
\end{array}$ & $\begin{array}{c}\mathrm{LP}^{*} \\
(\$ / \mathrm{MWh})\end{array}$ \\
\hline 1 & 0.00 & 132.00 & 77.00 & 20,000 \\
\hline 2 & -0.07 & 0.00 & 130.00 & 20,000 \\
\hline 3 & 0.14 & 230.00 & 0.00 & 20,000 \\
\hline 4 & -0.14 & 0.00 & 160.00 & 20,000 \\
\hline 5 & 0.02 & 0.00 & 115.00 & 20,000 \\
\hline 6 & 0.00 & 120.00 & 0.00 & 20,000 \\
\hline \multicolumn{2}{|c|}{ Total/Installed } & $482 / 482$ & $482 / 525$ & \\
\hline \multicolumn{2}{|c|}{$\begin{array}{c}\text { Average of Nodal } \\
\text { Prices }(\$ / M W h)\end{array}$} & \multicolumn{3}{|c|}{20,000} \\
\hline
\end{tabular}

TABLE VIII

POWER Flows OF THE TRANSMISSION LINES IN THE EQUILIBRIUM OF THE ELECTRICITY MARKET IN AUGMENTED TRANSMISSION SySTEM

\begin{tabular}{c|c|c|c}
\hline From & To & $\begin{array}{l}\text { Power } \\
\text { Flow (MW) }\end{array}$ & Capacity (MW) \\
\hline Bus1 & Bus2 & 17.39 & 40.00 \\
\hline Bus1 & Bus4 & 46.70 & 230.00 \\
\hline Bus1 & Bus5 & -9.09 & 60.00 \\
\hline Bus2 & Bus3 & -105.91 & 180.00 \\
\hline Bus2 & Bus4 & 17.63 & 50.00 \\
\hline Bus2 & Bus6 & -24.33 & 40.00 \\
\hline Bus3 & Bus5 & 124.09 & 320.00 \\
\hline Bus4 & Bus6 & -95.67 & 260.00 \\
\hline
\end{tabular}

TABLE IX

Financial WithHolding, PhysicAl WithHolding, AND the ThreE METRICS OF MARKET POWER IN TwO SCENARIOS OF THE STATUS QuO AND AUGMENTED TRANSMISSION SYSTEM

\begin{tabular}{|c|c|c|}
\hline Market Power Metric & $\begin{array}{c}\text { Status quo } \\
\text { transmission } \\
\text { system } \\
\end{array}$ & $\begin{array}{c}\text { Augmented } \\
\text { transmission } \\
\text { system } \\
\end{array}$ \\
\hline $\begin{array}{c}\text { Financial withholding } \\
(\$ / \mathrm{MWh}) \\
\left(\Delta \text { Price }_{\text {Distortion }}\right)\end{array}$ & 36,906 & $\begin{array}{c}19,980 \\
(46 \% \mathrm{DEC})\end{array}$ \\
\hline $\begin{array}{l}\text { Physical withholding } \\
\text { (MW) } \\
(\Delta \text { Quantity Distortion) }\end{array}$ & 848 & $798(6 \%$ DEC $)$ \\
\hline$A_{L}(\$ / \mathrm{h})$ & $47,257,900$ & $\begin{array}{l}25590,362 \\
(46 \% \text { DEC }) \\
\end{array}$ \\
\hline Overall profit of GenCos & $11,831,320$ & $\begin{array}{c}9,629,616 \\
(19 \% \text { DEC })\end{array}$ \\
\hline INC : Increase & DEC : Decreas & \\
\hline
\end{tabular}

consequence of the TNSP planning schedule. The overall reduction in market power is about $46 \%$, calculated based on the $A_{L}$ metric.

While the transmission planning schedule $n_{A L}=$ $(0,1,0,0,0,1,1,0)$ reduces the market power of the electricity market, the traditional mechanism of augmentation [10] does not approve any transmission planning schedule for the TNSP.

Fig. 7 shows offer curves of the GenCos in two scenarios of status quo and augmented transmission systems. Note that as a result of the augmentation, GenCo2 offers more of its capacity, which has an impact on GenCo 1 withholding some of its capacity.

Table X shows the GenCos' profits in two scenarios of status quo and augmented transmission system. 

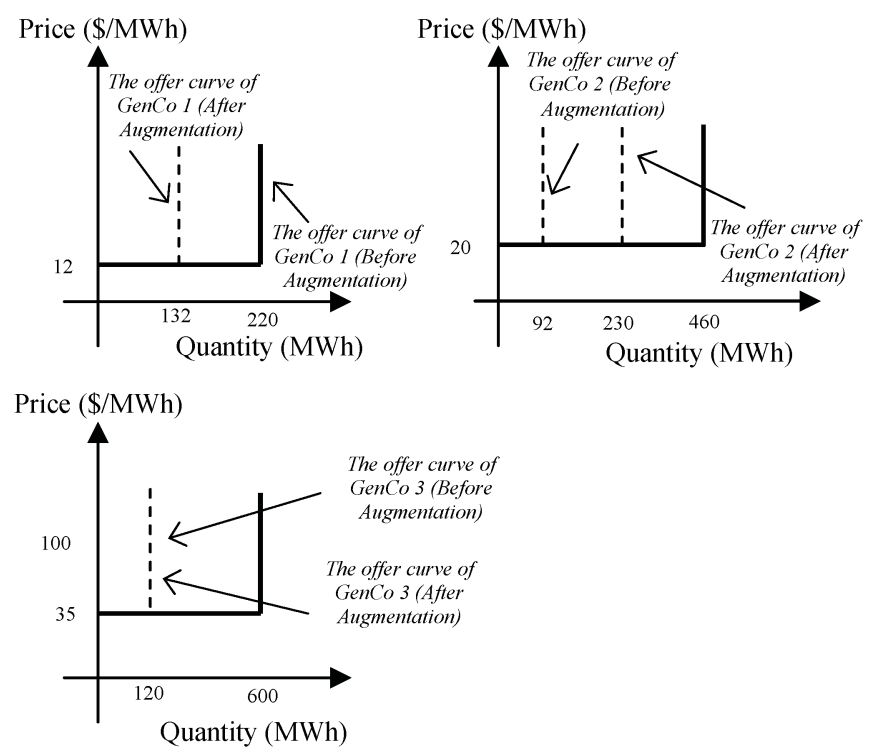

Fig. 7. Marginal cost curve (with bold lines) and the strategy curves of GenCos (with dashed lines) before and after transmission augmentation strategy by the proposed model.

TABLE X

GenCos’ Profits in Two Scenarios of Status Quo AND AUGMENTED TRANSMISSION SYSTEM

\begin{tabular}{l|c|c}
\hline & $\begin{array}{c}\text { Status quo Network } \\
(\$ / \mathrm{h})\end{array}$ & $\begin{array}{c}\text { Augmented Network, } \\
(\$ / \mathrm{h})\end{array}$ \\
\hline GENCO 1 PROFIT & $4,397,360$ & $2,638,416$ \\
\hline GENCO 2 PROFIT & $4,138,160$ & $4,595,400$ \\
\hline GENCO 3 PROFIT & $3,295,800$ & $2,395,800$ \\
\hline
\end{tabular}

If we solve the mathematical structure in (11) using the developed numerical solution in Section III, the pareto front of the TNSP transmission planning schedules would result in a 3-D figure as shown in Fig. 8.

The pareto front has 28 different planning schedules of the TNSP. These planning schedules are dominant alternative solutions of the TNSP for economics-based augmentation of the transmission system. Using $\$ 1500000$ as the TNSP revenue cap and ranking the pareto front solutions result in the vector $n_{\mathrm{MR}}=(0,1,0,0,0,1,1,0)$ as the TNSP solution.

The TNSP solution of $n_{\mathrm{MR}}=(0,1,0,0,0,1,1,0)$ selected based on the MR metric is the same as the one that was selected based on the developed $A_{L}$ metric. However, comparing Figs. 6 and 8 clearly shows two following advantages of the $A_{L}$ metric over the MR metric.

1) The $A_{L}$ metric can capture both the efficiency effect and the market power effect of transmission capacity in a single metric. This decreases the complexity of the TNSP mathematical structure. The mathematical structure of the transmission augmentation based on the $A_{L}$ metric has a twolevel structure, while the mathematical formulation of the transmission augmentation based on the MR concept has a three-level structure. This becomes a very important aspect in developing the numerical solution.

2) Two forms of exercising market power, financial and physical withholdings, are clearly modeled on the horizontal axis and vertical axis of the $A_{L}$ metric.

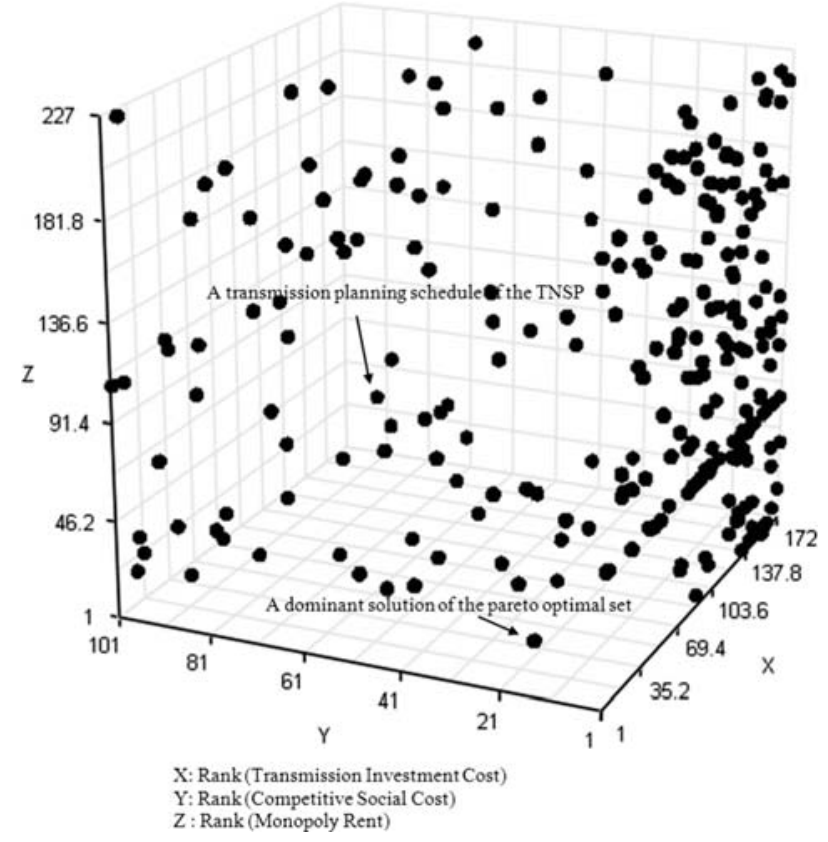

Fig. 8. Pareto front of the TNSP transmission planning schedules based on the transmission investment cost, $X$-axis, competitive social cost, $Y$-axis, and the MR, Z-axis.

TABLE XI

GENERATORS' DATA

\begin{tabular}{l|c|c}
\hline Generator & $\begin{array}{c}\text { Generating } \\
\text { capacity } \\
(\mathrm{MW})\end{array}$ & $\mathrm{c}(\$ / \mathrm{MWh})$ \\
\hline GenCo1 & 134 & 90 \\
\hline GenCo2 & 80 & 30 \\
\hline GenCo3 & 120 & 50 \\
\hline GenCo4 & 70 & 20 \\
\hline GenCo5 & 140 & 70 \\
\hline Total & 544 & \\
\hline
\end{tabular}

\section{Modified IEEE 14-Bus Example System}

To show the efficiency of the designed numerical solution in Section III in solving the developed structures of (11) and (12), the IEEE 14-bus example system is modified and employed. A comparison between the global solution of the problem and the best-found solution by the numerical method is carried out.

As in Section IV-B, a thorough economic study is carried out to clearly highlight the merits of the developed mathematical structures for capturing the efficiency effect and the market power effect of the transmission capacity.

The IEEE 14-bus example system has been modified to suit the purpose of study. The data of the system are presented in Tables XI-XIII. The single line diagram of the modified IEEE 14-bus example system is shown in Fig. 9.

The modified IEEE 14-bus example system has five GenCos, G1-G5, and 11 retailers, R1-R11, as shown in Fig. 9. Twenty transmission corridors support the electricity market trades to happen. The transmission network augmentation data for this study is presented in Table XIV.

As in Table XIV, the maximum number of circuits per transmission corridor is three circuits and $100 \mathrm{MW}$ per circuit. The 
TABLE XII

RETAILERS' DATA

\begin{tabular}{c|c|c}
\hline Retailer & $\begin{array}{c}\text { Demand } \\
\text { (MW) }\end{array}$ & VoLL (\$/MWh) \\
\hline R1 & 42 & 42,000 \\
\hline R2 & 80 & 50,000 \\
\hline R3 & 72 & 45,000 \\
\hline R4 & 14 & 11,000 \\
\hline R5 & 21 & 22,000 \\
\hline R6 & 49 & 40,000 \\
\hline R7 & 9 & 12,000 \\
\hline R8 & 6 & 10,000 \\
\hline R9 & 12 & 20,000 \\
\hline R10 & 26 & 30,000 \\
\hline R11 & 29 & 35,000 \\
\hline Total & 360 & \\
\hline
\end{tabular}

TABLE XIII

TRANSMISSION NETWORK DATA

\begin{tabular}{c|c|c|c|c}
\hline Line\# & From & To & Reactance (Ohm) & Limit (MW) \\
\hline 1 & Bus1 & Bus2 & 0.0006 & 40 \\
\hline 2 & Bus1 & Bus5 & 0.0022 & 40 \\
\hline 3 & Bus2 & Bus3 & 0.0020 & 40 \\
\hline 4 & Bus2 & Bus4 & 0.0018 & 40 \\
\hline 5 & Bus2 & Bus5 & 0.0017 & 40 \\
\hline 6 & Bus3 & Bus4 & 0.0017 & 40 \\
\hline 7 & Bus4 & Bus5 & 0.0004 & 40 \\
\hline 8 & Bus4 & Bus7 & 0.0021 & 40 \\
\hline 9 & Bus4 & Bus9 & 0.0055 & 40 \\
\hline 10 & Bus5 & Bus6 & 0.0025 & 40 \\
\hline 11 & Bus6 & Bus11 & 0.0020 & 40 \\
\hline 12 & Bus6 & Bus12 & 0.0025 & 40 \\
\hline 13 & Bus6 & Bus13 & 0.0013 & 40 \\
\hline 14 & Bus7 & Bus8 & 0.0017 & 40 \\
\hline 15 & Bus7 & Bus9 & 0.0011 & 40 \\
\hline 16 & Bus9 & Bus10 & 0.0008 & 40 \\
\hline 17 & Bus9 & Bus14 & 0.0027 & 40 \\
\hline 18 & Bus10 & Bus11 & 0.0019 & 40 \\
\hline 19 & Bus12 & Bus13 & 0.0019 & 40 \\
\hline 20 & Bus13 & Bus14 & 0.0034 & 40 \\
\hline & & & &
\end{tabular}

transmission investment costs are designed to suit the purpose of study.

Each GenCo has 15 strategies to choose from. These strategies are built up by varying the offered price from marginal cost to five times of the marginal cost and the offered quantity from $10 \%$ of capacity to the total capacity in steps of $10 \%$.

Table XV shows the settings of the developed numerical solution for solving the proposed mathematical structures in (10) and (11). The approximate competitive equilibrium of the electricity market is located at (544 MW, 70 \$/MWh). The equilibrium of the electricity market in the status quo transmission system is at (271 MW, 36806 \$/MWh). The GenCos reduce their capacity by $273 \mathrm{MW}$ and this raises the market price from $70 \$ / \mathrm{MWh}$ to $36806 \$ / \mathrm{MWh}$. This is equivalent to $A_{L}=20003480 \$ / \mathrm{h}$. The best-found pareto front of the TNSP, using the $A_{L}$, is shown in Fig. 10. Based on Fig. 10 and using $\$ 20000$ as the TNSP revenue cap, the vector $n_{A L}=(2,0,0,1,0,1,1,0,2,2)$ will be selected as the TNSP solution.

Table XVI compares the market power metrics of financial withholding, physical withholding, and the proposed $A_{L}$ metric in two scenarios of the status quo transmission system and the

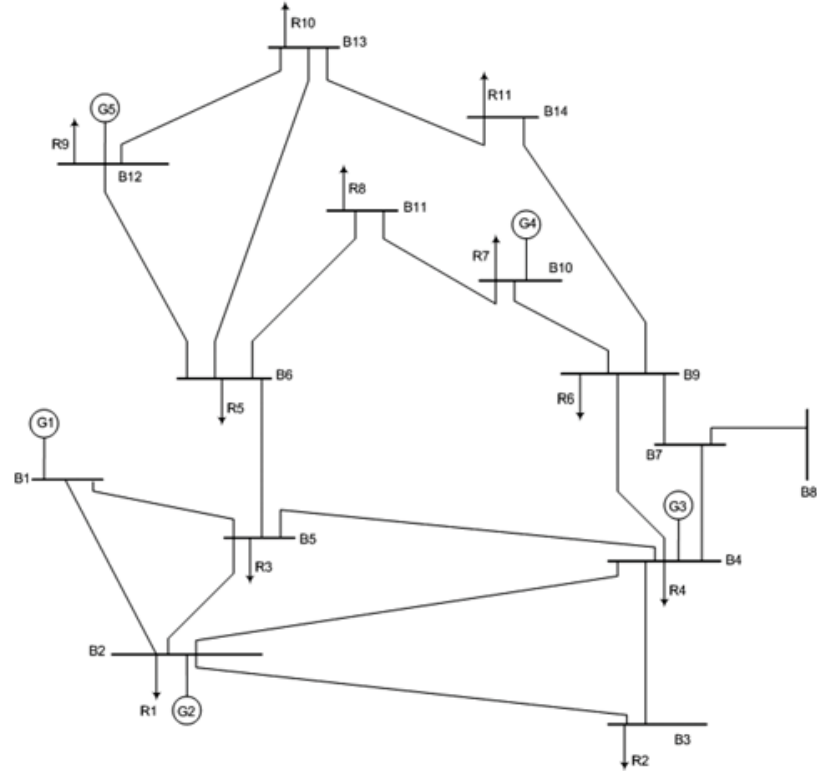

Fig. 9. Modified IEEE 14-bus example system.

TABLE XIV

TRANSMISSION NETWORK AUGMENTATION DATA

\begin{tabular}{c|c|c|c|c|c}
\hline Line\# & From & To & $\begin{array}{c}\text { Max. } \\
\text { number } \\
\text { of } \\
\text { Circuits } \\
\text { (Ckt) }\end{array}$ & $\begin{array}{c}\text { Capacity } \\
\text { (MW/Ckt) }\end{array}$ & $\begin{array}{c}\text { Transmission } \\
\text { Investment } \\
\text { cost (\$/Ckt) }\end{array}$ \\
\hline 1 & Bus1 & Bus2 & 3 & 100 & 4000 \\
\hline 2 & Bus1 & Bus5 & 3 & 100 & 2200 \\
\hline 3 & Bus2 & Bus3 & 3 & 100 & 3900 \\
\hline 4 & Bus2 & Bus4 & 3 & 100 & 1800 \\
\hline 5 & Bus2 & Bus5 & 3 & 100 & 2700 \\
\hline 6 & Bus3 & Bus4 & 3 & 100 & 1200 \\
\hline 7 & Bus12 & Bus13 & 3 & 100 & 2800 \\
\hline 8 & Bus13 & Bus14 & 3 & 100 & 3400 \\
\hline 9 & Bus1 & Bus12 & 3 & 100 & 1000 \\
\hline 10 & Bus10 & Bus3 & 3 & 100 & 1200 \\
\hline
\end{tabular}

TABLE XV

Setting Parameters of the DeVeloped Numerical Solution

\begin{tabular}{c|c}
\hline Setting parameter & Value \\
\hline Mutation probability of GA & 0.2 \\
\hline Crossover probability of GA & 0.8 \\
\hline Population size of GA & 15 \\
\hline Number of islands & 4 \\
\hline Migration topology & Directed Square \\
\hline Communication frequency & $1 /$ iteration \\
\hline Communication magnitude & 4 chromosomes \\
\hline Number of evolution of each island & 10 \\
\hline Mutation probability of IPGA & 0.5 \\
\hline Crossover probability of IPGA & 0.8 \\
\hline Population size of IPGA & 120 \\
\hline $\begin{array}{c}\text { Total number of iterations of IPGA } \\
\text { module }\end{array}$ & 5 \\
\hline
\end{tabular}

augmented transmission system. The overall profit of GenCos is calculated in the last row of Table XVI. As in Table XVI, the financial withholding and the physical withholding are decreased by $46 \%$ and $20 \%$, respectively. This is equivalent to $46 \%$ reduction in the market power. 


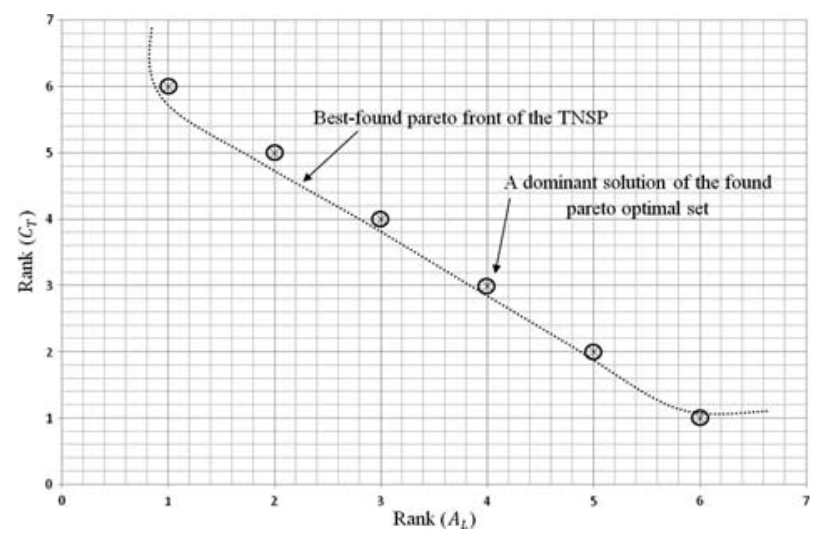

Fig. 10. Best-found pareto front of the TNSP based on the proposed $A_{L}$ metric and the transmission investment cost-modified IEEE 14-bus system.

TABLE XVI

Three Metrics of Market Power IN Two Scenarios of the Status Quo AND AUGMENTED TRANSMISSION SYSTEM

\begin{tabular}{c|c|c}
\hline Market Power Metric & $\begin{array}{c}\text { Status quo } \\
\text { transmission } \\
\text { system }\end{array}$ & $\begin{array}{c}\text { Augmented } \\
\text { transmission } \\
\text { system }\end{array}$ \\
\hline $\begin{array}{c}\text { Financial withholding } \\
(\$ / \mathrm{MWh})(\Delta \text { Price }\end{array}$ Distortion $)$ & 36,736 & $19,929(46 \% \mathrm{DEC})$ \\
\hline $\begin{array}{c}\text { Physical withholding }(\mathrm{MW}) \\
(\Delta \text { Quantity Distortion })\end{array}$ & 272 & $220(20 \% \mathrm{DEC})$ \\
\hline$A_{L}(\$ / \mathrm{h})$ & $20,003,480$ & $\begin{array}{c}10,856,776 \\
(46 \% \mathrm{DEC})\end{array}$ \\
\hline Overall profit of GenCos & $9,800,942$ & $\begin{array}{c}6,467,840 \\
(34 \% \mathrm{DEC})\end{array}$ \\
\hline INC $:$ Increase & $\mathrm{DEC}:$ Decrease \\
\hline
\end{tabular}

Fig. 11 shows offer curves of the GenCos in two scenarios of status quo and augmented transmission systems. This figure clearly shows the effect of the selected transmission augmentation schedule by the developed mathematical structure based on the $A_{L}$ metric on reducing market power.

In the augmented transmission system, the GenCo 1 reduces its offered price from 360 to 90 \$/MWh with $40.2 \mathrm{MW}$ as the offered capacity in both cases of before augmentation and after augmentation. The GenCo 2 increases the offered capacity to the market from 84 to $96 \mathrm{MW}$ and raises its offered price from 50 to $200 \$ / \mathrm{MWh}$. The GenCo 4 offers $21 \mathrm{MW}$ at $80 \$ / \mathrm{MWh}$ in the status quo transmission system, and offers its true marginal cost and capacity in the augmented transmission system. The GenCo 5 experiences a situation similar to the GenCo 1 in the two scenarios. Regarding the GenCo 2, the selected transmission planning schedule gives rise to its market power. Consequently, it withholds more capacity from the electricity market in the augmented transmission system than the status quo transmission system. Nevertheless, the system as a whole has improved significantly after augmentation.

However, Table XVII shows the best-found front of the TNSP based on the mathematical structure in (12). This structure uses the overall MR of the electricity market as a measure of the market power.

Using a revenue cap of $\$ 35000$, solution 5 will be selected.

Using solution 5 of Table XVIII, the efficiency of the electricity market measured by the competitive social cost is im-
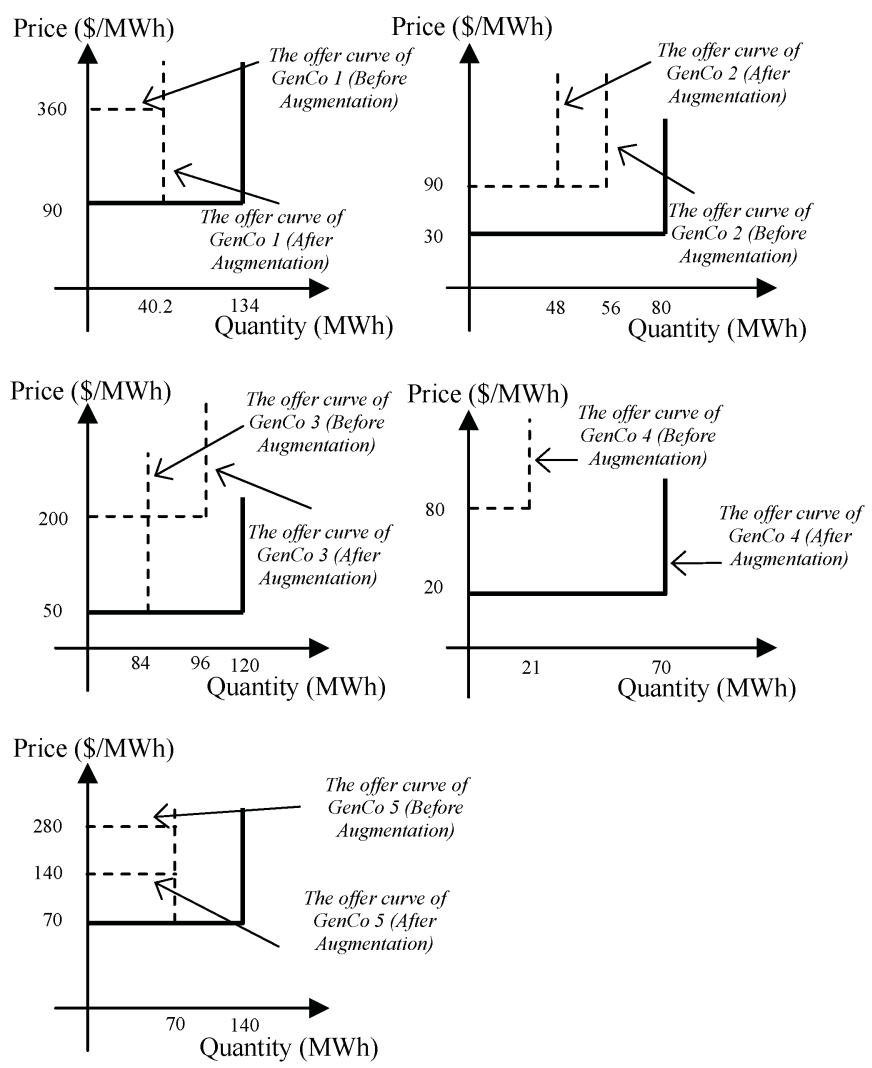

Fig. 11. Marginal cost curve (with bold lines) and the strategy curves of GenCos (with dashed lines) before and after transmission system augmentation by the proposed model.

TABLE XVII

DOMINANT SOlutions of THE BEST-Found Front BASED ON THE SECOND DEVEloped MATHEMATICAL STRUCTURE OF TRANSMISSION AUGMENTATION-OPTIMIZATION SET IN (12)

\begin{tabular}{c|c|c|c|c|c|c}
\hline From & To & $\begin{array}{c}\text { Solution } \\
1\end{array}$ & $\begin{array}{c}\text { Solution } \\
2\end{array}$ & $\begin{array}{c}\text { Solution } \\
3\end{array}$ & $\begin{array}{c}\text { Solution } \\
4\end{array}$ & $\begin{array}{c}\text { Solution } \\
\underline{5}\end{array}$ \\
\hline Bus1 & Bus2 & 3 & 0 & 2 & 0 & 2 \\
\hline Bus1 & Bus5 & 1 & 3 & 1 & 0 & 0 \\
\hline Bus2 & Bus3 & 3 & 2 & 2 & 0 & 3 \\
\hline Bus2 & Bus4 & 3 & 3 & 3 & 2 & 2 \\
\hline Bus2 & Bus5 & 0 & 3 & 1 & 0 & 0 \\
\hline Bus3 & Bus4 & 3 & 0 & 3 & 2 & 2 \\
\hline Bus12 & Bus13 & 0 & 2 & 0 & 3 & 0 \\
\hline Bus13 & Bus14 & 1 & 1 & 0 & 0 & 2 \\
\hline Bus1 & Bus12 & 2 & 1 & 0 & 0 & 0 \\
\hline Bus10 & Bus3 & 1 & 2 & 3 & 0 & 2 \\
\hline $\begin{array}{c}\text { Total TNSP } \\
\text { cost (\$) }\end{array}$ & 41,500 & 40,300 & 33,300 & 14,400 & 34,900 \\
\hline
\end{tabular}

proved by $14 \%$. Also, the market power is reduced by $33 \%$. In this case, the market power is measured by the MR.

These results show that both mathematical structures are successful in modeling the market power effect of transmission capacity. Accordingly, they can use transmission capacity for reducing market power in the electricity market.

\section{CONCLUDING REMARKS}

This paper proposes two mathematical structures for modeling market power in the mechanism of transmission system augmentation. The structures are derived based on the concepts 
TABLE XVIII

COMPETITIVE SOCIAL COST AND THE MR IN THE STATUS QUO AND AUGMENTED TRANSMISSION SYSTEM

\begin{tabular}{c|c|c}
\hline Metric & $\begin{array}{c}\text { Status quo } \\
\text { transmission } \\
\text { system }\end{array}$ & $\begin{array}{c}\text { Augmented } \\
\text { transmission } \\
\text { system }\end{array}$ \\
\hline $\begin{array}{c}\text { Competitive Social } \\
\text { Cost }(\$ / \mathrm{h})\end{array}$ & 19,051 & $\begin{array}{c}16,345 \\
(14 \% \mathrm{DEC})\end{array}$ \\
\hline Monopoly Rent $(\$ / \mathrm{h})$ & $9,755,549$ & $\begin{array}{c}6,555,589 \\
(33 \% \mathrm{DEC})\end{array}$ \\
\hline INC : Increase & DEC : Decrease \\
\hline
\end{tabular}

of simultaneous-move and sequential-move games in applied mathematics. A noncooperative decision system is employed to model the interaction of the TNSP, with the GenCos and the $\mathrm{MMC}$, in the process of transmission system augmentation. The Nash equilibrium is reformulated as an optimization problem. The multiple Nash equilibria are tackled through the introduced concept of worst Nash equilibrium. The quantity withheld and $\mathrm{MR}$, as two consequences of exercising the market power, are mathematically modeled. The quantity withheld is modeled by designing a metric termed L-Shape Area. This metric can model both financial withholding and physical withholding. The MR is modeled by finding the profits of the GenCos in two scenarios of the actual equilibrium and competitive equilibrium of the electricity market.

A numerical solution is developed to solve the mathematical structures. The numerical solution is a standard genetic algorithm, which has a nested IPGA.

The nested IPGA can effectively locate the Nash equilibria of the simultaneous-move game among the GenCos.

Two example systems are employed and carefully modified to clearly highlight the different perspectives of the proposed structures. Numerical results prove that the proposed structures are successful in modeling market power in the transmission augmentation algorithm. Accordingly, they can be considered as very good alternative frameworks for transmission network service providers and policy makers for improving efficiency and reducing market power in the electricity market.

\section{APPENDIX A}

Proof of theorem 1: Let $y_{i}$ be a strategy that belongs to a strategy space $\mathrm{Y}_{\mathrm{i}}$ and $\pi_{\mathrm{i}}$ be the profit function of player $i$ in game G. Also, let $y_{-i}$ be the strategy of all other players of the game $\mathrm{G}$ except player $i$. The variable $y^{*}=\left(y_{1}^{*}, y_{2}^{*}, \ldots, y_{i}^{*}, \ldots y_{n}^{*}\right)$ is the Nash equilibrium of the game $\mathrm{G}$ if for every player $i$ and for every strategy $y_{i}$, we obtained

$$
\begin{aligned}
\pi_{i}\left(y_{i}^{*}, y_{-i}^{*}\right) & \geq \pi_{i}\left(y_{i}, y_{-i}^{*}\right) \rightarrow M_{i}\left(y_{i}, y_{-i}^{*}\right) \\
& =\pi_{i}\left(y_{i}^{*}, y_{-i}^{*}\right)-\pi_{i}\left(y_{i}, y_{-i}^{*}\right) \geq 0 .
\end{aligned}
$$

If we define $M(y)=\sum M_{i}$, then

$$
M(y)=0 \leftrightarrow y=y^{*} .
$$

\section{APPENDIX B}

Proof of theorem 2:

$$
\begin{aligned}
& A_{L}=0 \Rightarrow G_{\max }\left(v_{c}+\Delta v\right)-G v=0 \Rightarrow \\
& \frac{v_{c}+\Delta v}{v_{c}}=\frac{G}{G_{\max }} \Rightarrow 1+\frac{\Delta v}{v_{c}}=\frac{G}{G_{\max }} \\
& \therefore(1) 1+\frac{\Delta v}{v_{c}}=\frac{G}{G_{\max }}, \quad(2) \frac{G}{G_{\max }} \leq 1, \quad(3) \Delta v \geq 0 \\
& \stackrel{(3)}{\rightarrow} \frac{\Delta v}{v_{c}}+1 \geq 1 \stackrel{(1)}{\rightarrow} \frac{G}{G_{\max }} \geq 1 \stackrel{(2)}{\rightarrow} G=G_{\max }(4) .
\end{aligned}
$$

Substituting (4) in (1) $\Rightarrow \Delta v=0$ or alternatively, we obtained $\left\|v-v_{c}\right\|_{2}=0$.

\section{ACKNOWLEDGMENT}

The authors would like to thank Dr. Biggar for his inputs and comments on the original version of this document. Dr. Biggar is an economist with the Australian Competition and Consumer Commission and the Australian Energy Regulator.

\section{REFERENCES}

[1] S. Stoft, Power System Economics, Designing Markets for Electricity. Piscataway, NJ: IEEE Press, 2002.

[2] D. Biggar, Economic Analysis of Power Systems, book under publication, Australian Competition and Consumer Commission, and Australian Energy Regulator.

[3] P. Joskow and R. Schmalensee, Markets for Power: An Analysis of Electric Utility Deregulation. Cambridge, MA: MIT Press, 1983.

[4] C. Wolfram, "Strategic bidding in a multi-unit auction: An empirical analysis of bids to supply electricity in England and Wales," RAND J. Econ., vol. 29, pp. 703-725, 1998.

[5] S. Borenstein, J. Bushnell, and S. Stoft, "The competitive effects of transmission capacity in a deregulated electricity industry," Power Working Paper PWP-040R, Univ. California Energy Inst., 1998.

[6] J. Bushnell, "Transmission rights and market power," Elect. J., pp. 77-85, 1999.

[7] P. Joskow and J. Tirole, "Transmission rights and market power on electric power network," RAND J. Econ., vol. 31, pp. 450-487, 2000.

[8] T. O. Nasser, Imperfect Markets for Power: Competition and Residual Regulation in the Electricity Industry. Cambridge, MA: MIT Press, 1997.

[9] F. Leveque, Competitive Electricity Market and Sustainability. Cheltenham, U.K.: Edward Elgar, 2007.

[10] T. O. Leautier, "Regulation of an electric power transmission company," Energy J., vol. 21, no. 4, pp. 61-92, 2000.

[11] T. O. Leautier, "Transmission constraints and imperfect markets for power," J. Reg. Econ., vol. 19, no. 1, pp. 27-54, 2001.

[12] G. Latorre, R. D. Cruz, J. M. Areiza, and A. Villegas, "Classification of publications and models on transmission expansion planning," IEEE Trans. Power Syst., vol. 18, no. 2, pp. 938-946, May 2003.

[13] G. B. Shrestha and P. A. J. Fonseka, "Congestion driven transmission expansion in competitive power markets," IEEE Trans. Power Syst., vol. 19 , no. 3, pp. 1658-1665, Aug. 2004.

[14] W. Lu, E. Bompard, R. Napoli, and X. Jiang, "Heuristic procedures for transmission planning in competitive electricity markets," Elect. Power Syst. Res., vol. 77, no. 10, pp. 1337-1348, Aug. 2006.

[15] The California ISO, Transmission Economic Assessment Methodology, California Independent System Operator, 2004.

[16] Frontier Economics, Evaluating Interconnection Competition Benefits, Sep. 2004.

[17] P. I. Caro-Ochoa, "Evaluation of the transmission congestion impact on electricity markets," M.Sc. thesis, Dept. Elect. Eng., Univ. Illinois, Urbana, 2003.

[18] R. D. Christie, B. F. Wollenberg, and I. Wangensteen, "Transmission management in deregulated environment," Proc. IEEE, vol. 88, no. 2, pp. 170-195, Feb. 2000. 
[19] A. F. Rahimi and A. Y. Sheffrin, "Effective market monitoring in deregulated electricity market," IEEE Trans. Power Syst., vol. 18, no. 2, pp. 486-493, May 2003.

[20] M. Amelin, "On Monte Carlo simulation and analysis of electricity markets," Ph.D. dissertation, Dept. Elect. Eng., R. Inst. Technol., Stockholm, Sweden, 2004.

[21] S. Nuchprayoon, "On power scheduling and strategic behaviour in electricity markets," Ph.D. dissertation, Dept. Elect. Eng., Georgia Inst. Technol., Atlanta, 2003.

[22] The California ISO, Transmission Economic Assessment Methodology, California Independent System Operator, 2004.

[23] C. D. Wolfram, "Measuring duopoly power in the British electricity sport market," Amer. Econ. Rev., vol. 89, pp. 805-826, 1999.

[24] J. Borenstein, B. Bushnell, and S. Stoft, "Measuring market inefficiencies in California's deregulated wholesale electricity market," Paper PWP-064 Univ. California Energy Inst..

[25] P. Joskow and E. Kahn, A Quantitative Analysis of Pricing Behaviour in California's Wholesale Electricity Market During Summer 2000. Cambridge, MA: MIT Press.

[26] T. Weise, Global Optimization Algorithms-Theory and Application. [Online]. Available: http://www.it-weise.de/.

[27] “GAMS User Guide” [Online]. Available: http://www.gams.com/docs/ document.htm.

[28] D. E. Goldberg, Genetic Algorithms in Search, Optimization, and Machine Learning. Reading, MA: Addison-Wesley, 1975.

[29] J. P. Li, M. E. Balazs, G. T. Parks, and P. J. Clarkson, "A species conserving genetic algorithm for multimodal function optimization," Evol. Comput., vol. 10, no. 3, pp. 207-234, 2002.

[30] D. Beasley, D. R. Bull, and R. R. Martin, "A sequential niche technique for multimodal function optimization," Evol. Comput., vol. 1, no. 2, pp. 101-125, 1993.

[31] F. Glover, "Tabu search—Part I," J. Comput., vol. 1, no. 3, pp. 190-206, 1989.

[32] D. E. Goldberg and J. Richardson, "Genetic algorithms with sharing for multimodal function optimization," in Proc. 2nd Int. Conf. Genetic Algorithms, 1987, pp. 41-49.

[33] C. Y. Lin and Y. J. Yang, "Cluster identification techniques in genetic algorithms for multimodal optimization," in Computer-Aided Civil and Infrastructure Engineering. Oxford, U.K.: Blackwell, 1998, vol. 13, pp. 53-62.

[34] W. N. Martin, J. Lienig, and J. P. Cohoon, "Island (migration) models: Evolutionary algorithms based on punctuated equilibria," in Handbook of Evolutionary Computation.

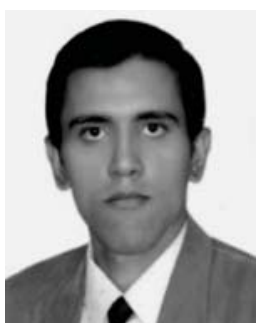

Mohammad R. Hesamzadeh (GS'08) received the B.Sc. and M.Sc. degrees in electrical engineering. He is currently pursuing the Ph.D. degree at Swinburne University of Technology, Melbourne, Australia.

His current research interests include power system economics, high-voltage transmission system planning and design, electricity market analysis, intelligent system applications in power systems, electrical distribution and rural system studies, and high-voltage engineering.

Mr. Hesamzadeh is a Member of the Computer and Analytical Methods Subcommittee of the Power System Analysis, Computing, and Economics Committee of the IEEE. He was the Vice Chair of the IEEE, Queensland Power and Energy Chapter, in 2008. He is a Professional Engineer in Australia.

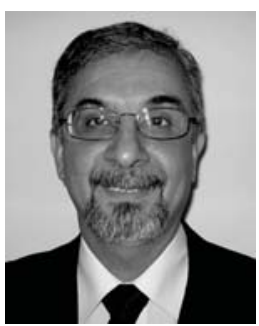

Nasser Hosseinzadeh (M'86) is currently with Swinburne University of Technology, Melbourne, Australia. He was a Senior Lecturer at the Central Queensland University in Australia, a Lecturer at Monash University Malaysia, and an Assistan Professor at Shiraz University, Iran. His research interests include power system analysis and planning, applications of intelligent control in power engineering, power system stability, wind energy systems, and engineering education.

Dr. Hosseinzadeh is on the Australian Panel APC System Development and Economics of CIGRE. He is a Registered Member of the Engineers Australia.

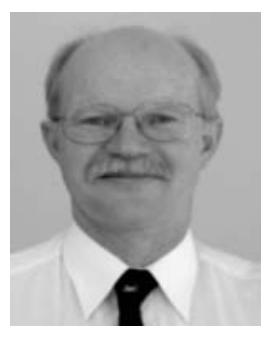

Peter J. Wolfs (M'80-SM'99) received the B.Eng. degree from Capricornia Institute of Advanced Education, Rockhampton, Australia, in 1980, the M.Eng. degree from Philips International Institute, Eindhoven, The Netherlands, in 1981, and the Ph.D. degree from the University of Queensland, Brisbane, Australia, in 1992.

He is currently the Western Power Chair of Power Engineering in the Department of Electrical and Computer Engineering, Curtin University, Bentley, Australia. His research interests include smart grids, distributed generation, power quality and harmonics, rural power supply, photovoltaic systems, power electronics, and railway traction power supply.

Prof. Wolfs is a Fellow of Engineers Australia. 